\title{
Management of oesophageal carcinoma with associated lung tuberculosis
}

\section{To the Editor:}

Several oesophageal diseases due to tuberculosis such as fistula [1, 2, 3], ulcer [4] and perforation [5] have been published in the literature, but very few studies have been published on lung tuberculosis associated with oesophageal carcinoma, which represents an uncommon therapeutic challenge.

Between 1988-2000, 14 patients with uni- or bilateral lung tubeculosis and associated middle-, upper- or lower-third oesophageal carcinoma were managed at our clinic. All patients, with the exception of two, had a marked body weight loss $(>10 \mathrm{~kg})$, and deeply altered pulmonary functions. Three types of treatment modalities were used in this series, subtotal or partial oesophageal resection and intubation.

One patient with left upper lobe cavernous lung tuberculosis and middle-third oesophageal carcinoma successfully underwent transhiatal resection and replacement with a gastric tube. Another lower-third tumour was resected through left thoracolaparotomy followed by Thomas-Merendino type jejunal interposition. The remaining 12 severely malnourished cases (one with respiratory fistula) were suitable only for palliative intubation, using our personal, minimal invasive surgical technique and designed tube [6].

No patient was lost postoperatively and no tube displacement developed in the survival period (4-7 months). The lung caverna of the first presented patient closed during the first postoperative year. The patient died 2 yrs after operation. All intubated patients have resumed on an oral soft diet.

But which type of surgery is advisable for these patients, who have less pulmonary reserve as a consequence of decreased forced expiratory volume in one second (FEV1), oxygen tension in arterial blood $\left(P \mathrm{a}, \mathrm{O}_{2}\right)$ and body weight, together with increasing susceptibility to alveolar collapse and atelectasis, accentuated by dysphagia with a similar effect on malnutrition, Serum albumin level and immune status?

Undoubtedly a perfect tumour staging focused on endoscopic ultrasound beside the usual diagnostic methods is the first requirement. On the other hand, based on the aspect of lung tuberculosis, Koch positivity or negativity, spirometry and diffusion capacity data and pulmonary reserve should be carefully evaluated. Malnutrition can lead to decreased respiratory muscle function and because after upper abdominal surgery, an integral part of oesophageal

Presented at the 1st Congress of the International Union against Tuberculosis and Lung Disease (IUATLD), Budapest, Hungary, April 12-15, 2000 replacement, diaphragmatic index and vital capacity will be markedly reduced for a week, sustaining muscular stength of respiratory muscle, through a proper nutrition, has a crucial importance in pulmonary care and for prevention of postoperative complications. In this manner, after a proper preoperative preparation by i.v. hyperalimentation, chest physiotherapy, metronidasole therapy and feeding jejunostomy in hopeful cases for oesophageal resection, the type of surgery should be determined by judgment of all these aspects with special attention to the response to preparation.

There is no doubt that only a minority of these patients are suitable for major surgical procedures such as oesophageal resection and replacement. Our experience shows that although pulmonary dysfunction is a major risk factor of oesophagectomy and substitution, the procedure is far better tolerated physiologically if transhiatal resection had been used. In the majority of extremely malnurished patients with a deeply affected pulmonary defence mechanism and immunological status, intubation may be considered as an effective, low-risk management. The multimodality approach to treatment is advocated for this high risk group of patients.

\section{Kotsis*, M. Póczi ${ }^{\#}$, K. Orbán*}

*Thoracic Surgical Clinic of Semmelweis University, Budapest, Pihenő út 1 and "Pulmonary Institute of Nógrádgárdony, Hungary.

\section{References}

1. Raghu G, Dillard D. Esophagobronchial fistula and mediastinal tuberculosis. Ann Thorac Surg 1990; 50: 647-649.

2. Macchiarini $\mathrm{P}$, Delmare $\mathrm{N}$, Beuzeboc $\mathrm{P}$, et al. Tracheooesophageal fistula caused by mycobacterial tuberculosis adenopathy. Ann Thorac Surg 1993; 55: $1561-1563$.

3. Ramo OJ, Salo JA, Isolauri J, Luodstarinen M, Mattila SP. Tuberculous fistula of the esophagus. Ann Thorac Surg 1996; 62: 1030-1032.

4. Fang HY, Lin TS, Cheng ChY, Talbot AR. Esophageal tuberculosis: a rare presentation with massive hematemesis. Ann Thorac Surg 1999; 68: 2344-2346.

5. Adkins MS, Raccuia JS, Acinapura AJ. Esophageal perforation in a patient with acquired immunodeficiency syndrome. Ann Thorac Surg 1990; 50: 299-300.

6. Kotsis L, Zubovits K, Vadász P. Management of malignant tracheoesophageal fistulas with a cuffed funnel tube. Ann Thorac Surg 1997; 64: 355-358. 